\title{
Gabriel García Márquez traducido: observaciones sobre la variación
}

\section{Introducción}

Cuando el gran filólogo colombiano Rufino José Cuervo, padre de la dialectología hispanoamericana, evocaba su concepción sobre la lengua, ya podíamos percibir en sus escritos una visión muy clara de la importancia de la variación: “cada lengua varía más o menos según las comarcas en que domina, y en cada una de ellas sigue su evolución propia: en la Península, no habla el natural de Castilla como el aragonés o el andaluz; ni, en América, el chileno como el mexicano o el colombiano" (Cuervo 3). Focalizándonos en la variación diatópica y en el nivel léxico, proponemos un estudio multidisciplinario de la realidad lingüística de Colombia a través de las obras literarias de Gabriel García Márquez, escritor emblemático colombiano y de la literatura hispanoamericana, digno representante de la literatura mundial gracias al universalismo y al exotismo de su obra.

Elementos diatópicos presentes en tres novelas del autor: Cien años de soledad, Crónica de una muerte anunciada y El amor en los tiempos del cólera, nos han permitido constituir un corpus lexicográfico diferencial con el fin de observar la variación diatópica en el léxico. También hemos conformado un segundo corpus en el que se puede observar con precisión la traducción al francés de estas formas y apreciar la manera como los traductores de las obras interpretan la variación. La traducción, pilar de la literatura mundial, nos permite acceder a una obra literaria mediada por un traductor. Pensamos que el análisis sistemático que proponemos, integrando la variación como eje del estudio, posibilita observar este proceso de "transcripción" a una lengua diferente que posee una variación diatópica con valores y matices propios.

\section{Marco teórico}

Este trabajo se enmarca en el campo de la lexicografía dialectal definida por Manuel Alvar Ezquerra y el de la metalexicografía fundada por el francés Bernard Quemada, aplicadas al estudio de obras literarias. Nos focalizamos en el

Liset Díaz Martínez, Université de Cergy-Pontoise

Ә Open Access. (C) 2020 Liset Díaz Martínez, published by De Gruyter. (c) BY-NC-ND This work is licensed under a Creative Commons Attribution-NonCommercial-NoDerivatives 4.0 International License.

https://doi.org/10.1515/9783110673678-009 
análisis de las voces marcadas en obras lexicográficas como colombianismos observando como esta variación es percibida e interpretada por los traductores y luego restituida en el texto traducido. Es decir que nuestro estudio hace también parte de la traductología. Nuestro material de trabajo está constituido por elementos diatópicos presentes en nuestro corpus, incluyendo igualmente como objeto de estudio las obras lexicográficas utilizadas en nuestros análisis.

La primera cuestión que abordaremos concierne a la diferencia entre español de Colombia y colombianismo. El español de Colombia es un dialecto historicoestructural que pertenece al complejo lingüístico del español panhispánico. Definir un dialecto es bastante difícil porque tradicionalmente ha sido asociado a una variedad informal o poco desarrollada de la lengua, la subordinación hace también parte del concepto y puede darle una connotación negativa. Pero podemos decir que un dialecto es equivalente a una lengua porque sus normas se realizan efectivamente en el habla. Un dialecto es, entonces, un sistema dependiente o subordinado de un complejo lingüístico, un resultado histórico de procesos convergentes o divergentes. Ese complejo lingüístico como lo conceptualiza José Juaquín Montes Giraldo, es una "lengua histórica" y lo consideramos como autónomo, unitario y social por naturaleza. El dialecto comparte con otros, entonces, una base estructural común y posee igualmente características diferenciales. En el caso del español, existe un complejo lingüístico que poco a poco se define y hacen parte de este todas las variantes nacionales autónomas de la lengua. Estas variantes son subsistemas diferenciados que cuentan con elementos comunes que permiten la comunicación entre hispanohablantes y también con particularidades regionales y locales que conocemos como diatopismos o "ismos". Muchas veces estos elementos son percibidos como marginales o vulgares del acervo lingüístico, pero, en realidad, no se definen por el nivel de lengua sino por la extensión geográfica de su uso.

En cada variante encontramos normas cultas, y el objetivo es estudiarlas y caracterizarlas saliendo de las barreras prescriptivas que pueden causar problemas de identidad y que niegan la riqueza de la lengua. Las normas cultas de cada país deben por lo tanto ser aceptadas y descritas en todos los niveles de la lengua. En este trabajo nos ocuparemos del nivel léxico, puesto que nos interesa su dinamismo y su tratamiento en las obras lexicográficas.

Los colombianismos son, entonces, fenómenos lingüísticos propios del español de Colombia, utilizados e identificados por los locutores nativos de esta variante del español. Esto significa que en el conjunto dialectal conformado por el español panhispánico, encontramos colombianismos, chilenismos, mexicanismos, argentinismos, españolismos, etc. También americanismos y, en este caso, estamos considerando fenómenos pertenecientes al español de América; sin embargo, definir el americanismo y el español de América es, en realidad, una tarea ardua. En efecto, estos conceptos que parecen tan simples y que se utilizan con tanta 
naturalidad no han podido ser definidos precisamente y pueden ser fuente de conflicto entre investigadores. La noción de español americano fue creada en oposición a otra llamada español peninsular a partir de elementos extralingüísticos y bajo una concepción de supuesta homogeneidad entre las variantes de América. Pero los estudios de estas variantes, todavía bastante fragmentados, no nos permiten promulgar científicamente esta homogeneidad lingüística y, por el momento, debemos mejor hablar de variantes hispanoamericanas y no de español americano. Algunos investigadores como José Pedro Rona nos explican también que este español no existe en sincronía porque no podemos encontrar fenómenos lingüísticos compartidos por todos los países de América y, al mismo tiempo, ausentes en todo el territorio español. El concepto de americanismo es igualmente problemático porque en sentido estricto representa rasgos lingüísticos usados en todo el territorio americano, pero, en realidad, se aplica a una cantidad enorme de rasgos que tienen una extensión geográfica muy variada. Si observamos la definición del diccionario de la Real Academia Española, esta extensión puede reducirse incluso a un solo país. Es decir que términos que tienen un uso bastante restringido también son considerados como americanismos y que una diferencia entre colombianismo, por ejemplo, y americanismo no sería bien marcada. Este concepto ha sido tratado por muchos lingüistas, mencionemos a Ambrosio Rabanales y de nuevo a José Pedro Rona, reconocidos como autores clásicos en el estudio del americanismo, quienes enuncian criterios de origen y de difusión geográfica para caracterizarlo.

En cuanto al americanismo en el nivel léxico, Jesús Gútemberg Bohórquez nos explica tres criterios principales de definición y de clasificación de estas palabras. Primero, el criterio de origen que incluye las palabras que nacieron en alguno de los países de América ya sea desde las lenguas indígenas, o creados en el territorio americano por los locutores hispanohablantes. El segundo criterio es enciclopédico e incluye términos que designan conceptos o realidades típicas del continente americano, como la fauna, la flora, por ejemplo. El último criterio es de uso y designa los términos que se utilizan en América, puede ser de forma global o contrastiva. Huguette Pottier-Navarro va más allá de de estos criterios y propone combinarlos con otros elementos como, por ejemplo, la extensión geográfica e integra igualmente una diferenciación de clasificación definiendo criterios intralingüísticos y extralingüísticos. Como vemos, muchas propuestas han explorado la definición de esta noción, y actualmente todas son válidas en los estudios lexicográficos.

Ahora vamos a focalizarnos en los diccionarios y estudiaremos como estas obras manejan el léxico definido como americano. Hablemos primero de dos tipos de diccionarios que tratan este léxico, los globales que utilizan el método global en la elección de su nomenclatura, y los contrastivos que se basan en 
el método diferencial. Es decir que eligen sus entradas comparándolas con otras obras lexicográficas, en cambio los globales no hacen ninguna comparación e incluyen directamente el léxico que desean definir. En el caso del español, los dos métodos se han utilizado, pero de manera muy particular. Generalmente, cuando un diccionario presenta el léxico de un país americano, las entradas se eligen usando el método diferencial. Es por esto que la mayoría de los diccionarios de las variantes americanas son diccionarios de "ismos" y no diccionarios globales. Los únicos diccionarios de este tipo corresponden a las variantes argentina y mexicana. De hecho, el Colegio de México milita por este tipo de diccionario y lo ha ya informatizado para proponer su uso libre en la web, se trata del Diccionario del Español de México o DEM (http://dem.colmex.mx/).

El tratamiento del léxico español de España se basa tradicionalmente en el método global. Muchas de las obras clásicas, académicas o no académicas, se han convertido en "diccionarios generales" que han poco a poco incluido una gran cantidad de léxico americano, sobre todo a partir del siglo XIX cuando las colonias americanas se emanciparon y la cuestión de la inclusión de los diatopismos en las obras lexicográficas se volvió argumento político, económico y sobre todo comercial. Siempre han existido voces americanas en los diccionarios globales del español de España, pero el siglo XIX aportó la inclusión de las marcas diatópicas americanas en estos diccionarios, con la obra pionera de Vicente de Salvá, publicada en 1846. Estas marcas han sido alabadas y también criticadas, su uso se generaliza pero parece todavía muy intuitivo y sin bases teóricas bien afincadas.

En cuanto a la metodología de los diccionarios diferenciales de las variedades americanas, hemos dicho que se basan en el contraste con otras obras lexicográficas. Estas corresponden tradicionalmente a diccionarios del español de España y sobre todo al diccionario académico. Estos diccionarios diferenciales aparecen al final del siglo XIX y representan una evolución importante de la lexicografía americana que producía sobre todo vocabularios y diccionarios de voces provinciales o provincialismos, que presentaban generalmente elementos exóticos del léxico americano con algunos apuntes enciclopédicos. También existían vocabularios o diccionarios de barbarismos o de voces corrompidas que mostraban el léxico americano como una desviación de la norma culta, es decir la norma de España, y que "ayudaban" a identificar estas voces americanas para corregirlas dando la equivalencia española correspondiente. En el siglo XX, gracias a los avances de la teoría lingüística, se comprende que la variación es inherente a la lengua, que las variantes americanas no son una corrupción y que cada una de ellas presenta normas cultas que pueden ser descritas y analizadas cualitativa o cuantitativamente. También un avance teórico importante es la concepción del español de España como variante de la lengua y no como núcleo prestigioso del complejo dialectal del español. En 
realidad, esta concepción es la que interviene en la realización de diccionarios diferenciales de variantes americanas y designa al español de España como modelo de comparación.

Hemos dicho que observaremos la variación diatópica en las obras literarias estudiadas para luego analizar cómo esta variación es tomada en cuenta por los traductores y cuáles estrategias son utilizadas para reconstituir el mensaje del autor. La lexicultura o cultura que se moviliza y se actualiza por las palabras, concepto presentado por Galisson, juega aquí un papel importante porque pensamos que cada lexema posee valores implícitos que son marcados por la pertenencia a una cultura particular. La dificultad de la traducción se presenta al intentar adaptarse a otra lengua que posee una variación como existe en todas las lenguas, pero con valores y cargas culturales diferentes. El léxico colombiano utilizado por Gabriel García Márquez es frecuentemente marcado y posee valores culturales de su caribe natal, describe particularidades lingüísticas de esa zona colombiana, costumbres, incluso olores, comidas típicas, etc. Es por eso que ese léxico debe ser tratado con mucha atención para tratar de conservar esos valores lexiculturales tan representativos de la variante descrita. Sin embargo, el autor de un texto traducido, como el de cualquier otro texto, tiene que también pensar en el público al cual va dirigido su traducción y a los valores lexiculturales de las palabras en el texto meta. Es por eso que la variación es un reto para el traductor.

\section{Obras lexicográficas utilizadas}

Nuestras observaciones sobre el léxico colombiano se fundamentan en obras lexicográficas diferenciales y globales, tres diccionarios de colombianismos y dos generales de la lengua española. El primer diccionario diferencial es el Nuevo diccionario de colombianismos publicado por el ICC en Bogotá en 1993. Este diccionario es una obra de referencia del léxico colombiano que hace parte del proyecto Nuevo diccionario de americanismos iniciado y dirigido por Günter Haensch y Reinhold Werner de la Universidad de Augsburgo. Es también la primera obra publicada de este proyecto cuya idea era producir diccionarios diferenciales en todos los países de América para ayudar al conocimiento léxico de todas variantes del continente. Se han publicado hasta ahora cinco diccionarios contrastivos y se preparan todavía tres, pero desafortunadamente el fallecimiento de los dos directores del proyecto y la falta de patrocinio para las últimas obras deja un panorama incierto para la finalización y publicación de estos trabajos. 
En el Nuevo diccionario de colombianismos, cada entrada se analiza de manera minuciosa y se describe con un juego de marcas gramaticales y sociolingüísticas bastante interesantes. Se mencionan igualmente marcas regionales, sinónimos y equivalencias, incluso en el español de España. En el prólogo de la obra se encuentran igualmente varios elementos y explicaciones lingüísticas de gran interés para los que estudian el léxico colombiano y para los que usan el diccionario. También al final de la obra, encontramos tres índices, el primero, muy extenso, presenta palabras del léxico de España y su equivalente en el léxico colombiano; los dos siguientes indican elementos enciclopédicos sobre la botánica y la zoología.

La segunda obra lexicográfica diferencial es el Breve diccionario de colombianismos de la Academia Colombiana de la Lengua que ha sido editado cuatro veces, publicado por primera vez en 1975 bajo la coordinación de José Antonio León, director de la Comisión de Lexicografía en esa fecha. La última edición revisada ha sido presentada en el año 2012 por la Comisión de Lingüística de esa Academia. Como su título lo indica es un trabajo poco extenso, pero de una gran calidad de redacción, coordinado por Carlos Patiño Rosselli, quien presenta la obra y explica lo que se entiende por colombianismo en el diccionario, es decir las palabras del léxico colombiano que no pertenecen a la lengua general. Pero ¿dónde se encuentra ese léxico general? Según el coordinador de la obra, en el diccionario de la Real Academia Española, que es la base de comparación del Breve diccionario de colombianismos. También se presentan las diferentes marcas gramaticales y sociolingüísticas, marcas regionales, y en algunas entradas además de la definición hay ejemplos tomados de obras literarias o forjados por los lexicógrafos. Las fuentes aparecen al final de la obra, asimismo una bibliografía del léxico colombiano y un anexo con los gentilicios de los diferentes departamentos del país. Esta obra se adquiere gratuitamente en la página de la Academia Colombiana.

El último diccionario diferencial es el Diccionario comentado del español actual en Colombia de Ramiro Montoya, tercera edición publicada en Madrid en 2006 por la editorial Vison Net, Colección Diccionarios. En la presentación de la obra se habla del español colombiano como variedad lingüística y en la introducción el autor explica las claves de lectura del diccionario. Las definiciones son redactadas de forma simple pero clara, sin embargo, hay marcas gramaticales que no se usan sistemáticamente en las acepciones. Encontramos igualmente marcas sociolingüísticas y regionales, ejemplos forjados en algunas entradas y notas de uso o de pronunciación. Esta tercera edición incluye dos suplementos léxicos, uno sobre el parlache o jerga que tiene sus raíces en las pandillas de jóvenes de Medellín, otro que compila léxico o expresiones que 
se usan principalmente en Madrid y no en Colombia, y algunas expresiones colombianas que no se usan en Madrid.

En cuanto a los diccionarios generales, empleamos el Diccionario de la lengua española (DLE a partir de aquí) de la Real Academia publicado en $2014 \mathrm{y}$ actualizado regularmente en la página Internet de esta institución. Corresponde a la vigesimotercera edición o edición del tricentenario. Es interesante anotar que en el preámbulo de la obra se señala la colaboración con las academias de América y de Filipinas y se evoca la unidad de la lengua española. Además, se presenta de manera muy general el trabajo de las Academias Americanas en cuanto a la inclusión de americanismos en el DLE. Este diccionario es un resultado histórico y cultural de una Academia que se funda en 1713 y que produce una serie de obras prescriptivas que comienzan con la publicación del primer tomo del Diccionario de autoridades en 1726. Actualmente, el titulo de la obra ha evolucionado y el diccionario se presenta como "general", descriptivo y sincrónico, con aproximadamente 93000 entradas y 195000 acepciones. Después del preámbulo, encontramos una serie de páginas que nos explican la forma de usar el diccionario, la estructura de los artículos lexicográficos, un juego de marcas complejo que incluye variedades americanas y regionales de España. Las marcas americanas, además de nombrar países, designan zonas más extensas como por ejemplo América Central o América. Un artículo puede ser muy complejo con información etimológica, varias acepciones y diferentes tipos de marcas.

El Pequeño Larousse ilustrado de 2012 hace también parte de los diccionarios generales utilizados. Esta obra es particular porque es un diccionario de lengua que presenta a la vez elementos enciclopédicos, en el artículo lexicográfico vemos las marcas, las informaciones etimológicas y la definición, a veces acompañados de ilustraciones, mapas, tablas o fotos. Esta edición es interesante porque corresponde a la del centenario puesto que la edición española del Petit Larousse illustré aparece en 1912 y es una adaptación hecha por Miguel de Toro y Gisbert. En esa época la obra seguía la nomenclatura de la Real Academia Española y contenía más de 10000 americanismos. En cuanto a las marcas del léxico de las variedades americanas, encontramos todos los países del continente y algunas con zonas más extensas como América, América Central o América Meridional. Para la lengua francesa, utilizamos las definiciones dadas por el Centro Nacional de Recursos Textuales y Lexicales o CNRTL. Este gran centro de lingüística asociado a laboratorios de investigación franceses agrupa diferentes obras lexicográficas en un portal léxico de acceso libre (http://www. cnrtl.fr/). 


\section{Novelas y traductores}

Como lo hemos ya mencionado, nuestro trabajo se focaliza en tres obras del escritor colombiano Gabriel García Márquez: Cien años de soledad, Crónica de una muerte anunciada y El amor en los tiempos del cólera. Consideramos que estas poseen elementos léxicos propios de la variedad colombiana que nos han servido para constituir un corpus léxico de colombianismos. Cien años de soledad, obra maestra del autor, fue publicada en 1967 en Argentina por la editorial Sudamericana y se ha convertido en clásico de la literatura mundial con más de 50 millones de ejemplares vendidos en todo el mundo. Gracias a esta obra, como lo evoca Ospina, Colombia, un país que resultaba olvidado, lejano, incluso "inquietante y paradójico", aparece de repente en la escena mundial. La historia de su redacción es apasionante y ampliamente conocida, Gabriel García Márquez explicaba que vivía modestamente en México con su esposa y que su situación económica era difícil, incluso no pudo enviarle a su editor Francisco Porrúa la totalidad del manuscrito porque no tenía los medios financieros para hacerlo. La obra fue un éxito inmediato y a pesar de que el autor no tenía un reconocimiento internacional fuera del ámbito latinoamericano, las traducciones de la obra aparecen rápidamente y se convierten a su vez en éxitos literarios. Como lo explica Marling, esta notoriedad es en gran parte ganada gracias a sus "gatekeepers" (guardianes): amigos, escritores, agentes, traductores, editores, etc., que a su modo contribuyeron al renombre del autor y ayudaron a moldear su imagen, primero en Colombia y luego a nivel internacional.

En Francia la situación fue diferente, la editorial Seuil tenía una colección conocida como "Cadre vert" en donde se publicaba la literatura extranjera traducida. Esta colección (que todavía existe) se focalizaba al principio en obras alemanas, pero fue poco a poco abriéndose a otras lenguas como el inglés y el español. Claude Durand, director de colección en esa editorial, conoce la novela de Gabriel García Márquez, según Dosse, gracias a Severo Sarduy que trabajaba allí como responsable de la sección española. Durand decide comprar los derechos de la traducción al francés y traducir la obra con la ayuda de su esposa Carmen; la novela traducida aparece en 1968 en Francia. La respuesta del público francés, como lo comenta Dosse, es muy matizada, las ventas de la obra son relativamente bajas aunque la crítica es buena. A principios de los años 70 la situación cambia y las ventas aumentan, la obra se convierte en un éxito para la casa editora pasando rápidamente a un millón de ejemplares vendidos. La reputación internacional del autor aumenta y los lectores franceses comienzan a apreciar profundamente al escritor colombiano. La colaboración entre Gabriel García Márquez y la casa editora Seuil se acaba rápidamente 
puesto que Claude Durand no puede adquirir los derechos de la traducción de las otras obras del autor porque que su precio había aumentado considerablemente. Claude Durand toma esto como un engaño imperdonable que modifica su percepción del escritor colombiano. Jean-Claude Fasquelle adquiere los derechos para la editorial Grasset y publica El otoño del patriarca y Crónica de una muerte anunciada.

Claude Couffon traduce estas obras y evoca su trabajo con la obra Crónica de una muerte anunciada que pudo traducir sin muchas dificultades puesto que el texto le parece muy claro y eficaz, es por esto que en Francia la obra fue publicada en 1981, es decir en el mismo año de la publicación en español. Claude Couffon es un hispanista reconocido que tradujo varias obras del autor colombiano. Un año después de esta publicación, Gabriel García Márquez recibe el premio Nobel de literatura y es aclamado mundialmente. Pero en Francia algunos periodistas lo atacan públicamente y artículos difamatorios son publicados en revistas como el Figaro magazine. Grasset continúa a publicar las novelas del autor; El amor en los tiempos del cólera aparece en Francia en 1987, dos años después de la publicación en español. Annie Morvan, traductora de la obra, conoce a Gabriel García Márquez en 1981 y el autor la cautiva inmediatamente. En esa época Le Nouvel Observateur le propone traducir un cuento del autor al francés y puesto que este se encontraba en París pudieron conocerse para trabajar en ese proyecto. Así se inicia una colaboración activa y una amistad inquebrantable. Gabriel García Márquez establecía generalmente lazos fuertes con sus traductores y los incitaba a crear porque le interesaba que su universo fuera comprendido por el lector en cualquier idioma.

\section{Corpus}

\subsection{Constitución del corpus}

Gracias al estudio de las obras en español y en francés constituimos un corpus inicial de trabajo en español. Luego, un estudio diccionárico nos permitió pulir el corpus inicial integrando o suprimiendo entradas. Paralelamente construimos un corpus en francés que contiene las traducciones del corpus español. Seguir el rastro de estas traducciones fue algunas veces complejo y necesitaba una atención particular. Actualmente contamos con dos bases de datos paralelas que contienen 800 palabras cada una, este número no es fijo y puede modificarse por varias razones. Primero, porque la nomenclatura de los diccionarios de colombianismos es bastante restringida y también porque en los diccionarios generales el léxico de 
las variantes americanas no aparece siempre con una marca diatópica. Algunas veces, una investigación diacrónica es necesaria para conocer el origen de la palabra y para identificar el uso colombiano. También, la forma de definir un colombianismo, es decir un "ismo" como lo hemos indicado en el marco teórico, entra en juego porque podemos caracterizarlo de una manera restrictiva o de forma amplia. No hemos incluido en el corpus expresiones fijas, pero las hemos identificado y en cambio, si hemos incluido palabras compuestas. Veamos, entonces, algunas observaciones sobre los datos obtenidos.

\subsection{Observaciones sobre el corpus}

Una vez creados los corpus paralelos en español y en francés, podemos compararlos y forjarnos una idea de la variación en general y de la traducción de la variación en el caso francés. Comentaremos algunos aspectos que nos parecen interesantes desde el punto de vista lexicultural.

Para empezar, queremos mencionar las voces de la fauna y de la flora que son americanismos de origen según la tipología definida por Jesús Gútemberg Bohórquez. Sin embargo, no podemos decir que la procedencia de estas palabras sea colombiana, pero las encontramos en los diccionarios diferenciales de nuestro estudio y por lo tanto las hemos incluido en nuestro trabajo. Además, pensamos que la definición de los “ismos" (colombianismos) no debe ser restrictiva, entonces, estas voces ganan su lugar en nuestro corpus sin problema alguno. Generalmente, éstas no presentan ninguna dificultad para traducirlas porque muchas de ellas han pasado al léxico francés como extranjerismos, a veces de forma directa. En los diccionarios generales, la marca americana no aparece en este tipo de palabras y solo podemos fiarnos en la etimología puesto que el origen de la lengua amerindia sí se explicita. Algunas veces, la definición del término también incluye indicaciones sobre su procedencia, usando frases como “originario/a de América”. Veamos algunos ejemplos (Imágenes 1 a 6) con las entradas "yuca” y "guayaba” que se encuentran en los dos diccionarios generales y en los diccionarios de colombianismos. En el Pequeño Larousse ilustrado algunas imágenes o fotos pueden acompañar la definición, siendo esto una característica de ese diccionario.

Finalmente, el Diccionario comentado del español en Colombia (que llamaremos DC), presenta una definición que ya hace parte del universo de García Márquez (ver Imágen 7).

Como lo explicamos anteriormente, estos términos no poseen marca diatópica en los diccionarios generales y se conserva únicamente la etimología de la lengua indígena, a veces con indicaciones del origen en la definición. En el corpus francés 
YUCA s.f. (voz taína). Planta liliácea de origen americano parecida al áloe, aclimatada en los países templados y con cuya raíz se elabora una harina alimenticia.

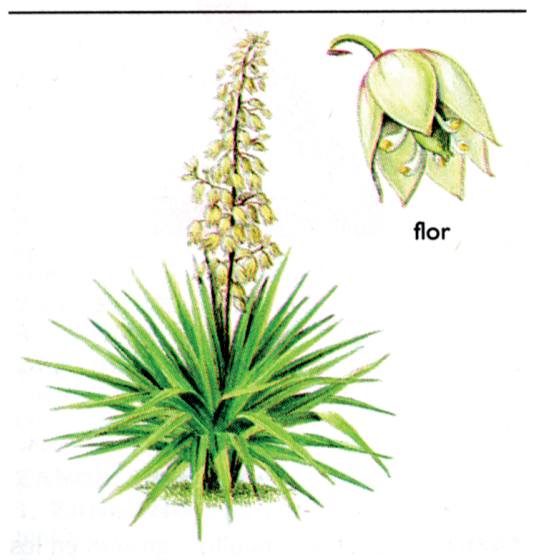

YUCA

Imagen 1: Pequeño Larousse ilustrado ("Yuca 1053").

GUAYABA s.f. Fruto del guayabo. 2. Antillas, Colomb., Nicar., Salv. y Urug. Fig. y fam. Mentira, embuste.

Imagen 2: Pequeño Larousse ilustrado (“Guayaba 504”).

encontramos todas las ocurrencias de la palabra "yuca" (6) traducidas como "manioc", palabra de origen tupí que entra directamente al francés (sin pasar por el español) a partir del siglo XVI. Las del término "guayaba" (3) se traducen "goyave", término que entra al francés en el siglo XVI por medio de una traducción de una obra del historiador español Gonzalo Fernandez de Oviedo y Valdés. Observamos, entonces, que la traducción de estas palabras es bastante simple y el término traducido conserva valores diatópicos americanos. Sin embargo, algunos americanismos de origen causan dificultades al traductor. Consideremos el caso del término "guacamaya" (ave) que tiene 11 ocurrencias en nuestro corpus y que aparece en los diccionarios que hemos venido mencionando. En España el término "guacamayo" tiene uso preferencial, como lo indica en el NDC la abreviación "E”: [E: guacamayo]. Pero en Colombia "guacamayo" designa un árbol (ver Imágenes 8 a 10).

El término se encuentra en el corpus francés traducido como "perroquet" con 8 ocurrencias y "cacatoès" con 3 ocurrencias. Pero usar "perroquet" despoja a esta realidad, que correspondería a "ara" en francés, de varias de sus características distintivas como sus colores típicos, su tamaño y su cola con plumaje largo. Si observamos la definición de "ara" en el CNRTL, encontramos 
yuca

De or. taíno.

1. f.. Planta de América tropical, de la familia de las liliáceas, con tallo arborescente, cilíndrico, lleno de cicatrices, de hasta dos metros de altura, coronado por un penacho de hojas largas, gruesas, rígidas y ensiformes, que tiene flores blancas, casi globosas, colgantes de un escapo largo y central, y raíz gruesa, de la que se saca harina alimenticia, y que se cultiva en Europa como planta de adorno.

2. f. Especie de mandioca.

3. f. colog. C. Rica. embuste (\| mentira).

4. f. Cuba, El Salv. y Nic. Raíz de la yuca que se come cocida en diversos platos típicos.

5. f. El Salv..... deuda (\| obligación de pagar).

6. f. El $\mathrm{S}$ al.... Cosa muy difícil de hacer.

andar de yuca un militar

1. loc. verb. $R . D o m$. Vestirse de paisano con fines particulares.

como yuca para mi guayo

1. loc. adv. colog. P. Rico. Con cuidado y esmero.

dar alguien yuca

1. loc. verb. colog. EC. Hacer un corte de mangas.

hacer alguien yuca

1. loc. verb. colog. Ec. Hacer un corte de mangas.

2. loc. verb. $R, D o m$. Cortejar a la enamorada.

meter una yuca

1. loc. verb. Nic. Amenazar con un daño.

ser alguien de yuca y ñame

1. loc. verb. Cuba. Ser severo, riguroso e intransigente.

bobo de la yuca

Imagen 3: DLE (“Yuca”).

\section{guayaba}

Voz arahuaca.

1. f... Fruto del guayabo, que es de forma aovada, del tamaño de una pera mediana, de varios colores, y más o menos dulce, con la carne llena de unos granillos o semillas pequeñas.

2. f. Conserva o jalea hecha con guayaba.

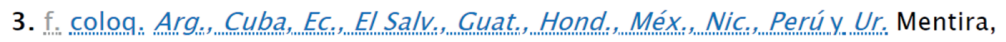
embuste.

4. f. El Salv. retentiva.

Imagen 4: DLE (“Guayaba”). 
estas características reconocidas igualmente en la cultura francesa. La traducción “cacatoès", utilizada una vez por los esposos Durand y dos veces por Annie Morvan, se aleja aún más del texto español porque representa un tipo de ave que no es originario de América, y un término que no es por lo tanto un americanismo de origen.

yuca $f$ tamb bot Planta de la familia de las euforbiáceas que alcanza hasta $2 \mathrm{~m}$ de alto. Tiene hojas palmeadas, de lóbulos profundos y flores pequeñas, poco vistosas. Su raíz tuberosa forma parte de la alimentación básica de los colombianos. Se cultivan numerosas variedades en climas cálidos y templados (Manihot esculenta) [cient: mandioca, tapioca]. | Tubérculo comestible de esta planta. * conseguir / ganarse la $\sim$ E- coloq Trabajar para conseguir los medios neccsarios de subsistencia $[E$, Col $+:$ ganarse el pan; $\mathrm{Col}+$ : conseguir / ganarse la papa]. I| sacar las s E-Boy, Cund, Huila, Llanos, NStder, Tol, Valle coloq Hacer sonar las articulaciones de los dedos de una mano, tirando de ellos con la otra $[E, A n t$, Risar: sacar (las) novias].

Imagen 5: Nuevo diccionario de colombianismos que llamaremos NDC ("Yuca 421-422").

guayaba $f E$ - Fruto del $\rightarrow$ guayabo, con el cual se preparan dulces, jaleas y el $\rightarrow$ bocadillo. | Grano de café, de mala calidad, por haberse secado en el cafeto antes de la cosecha. * palo de $\sim E$ - bot Árbol de la familia de las mirtáceas, de hasta $7 \mathrm{~m}$ de alto, de flores blancas, pequeñas, y frutos amarillos y globosos, comestibles ( $\rightarrow$ guayaba), de pulpa de color blanco o rosado, con numerosas semillas. La corteza de su tronco es de color café rojizo. El árbol crece silvestre o cultivado en climas cálido y templado (Psidium guayaba) [Col $+:$ guayabo]. $\| \sim$ agria $E$ - bot Fruto del $\rightarrow$ guayabo agrio.

Imagen 6: NDC (“Guayaba 210”).

Guayaba s. Fruta de muy delicioso sabor y olor.

(Se toma como fruta, en mermeladas o jalea, en jugo. Su consumo es tan extendido que García Márquez define "el olor de la guayaba" como la nostalgia del colombiano por su país). Véase bocadillo de guayaba.

Imagen 7: DC (“Guayaba 143”). 


\section{guacamayo}

\section{Del taíno huacamayo.}

1. m. Ave de América, especie de papagayo, del tamaño de la gallina, con el pico blanco por encima, negro por debajo, las sienes blancas, el cuerpo rojo sanguíneo, el pecho variado de azul y verde, las plumas grandes exteriores de las alas muy azules, los encuentros amarillos, y la cola muy larga y roja, con las plumas de los lados azules.

Imagen 8: DLE (“Guacamayo”).

GUACAMAYO s.m. (voz arauaca). Ave de América del Sur parecida al papagayo, de unos $90 \mathrm{~cm}$ de long., cola larga y plumaje de colores vivos.

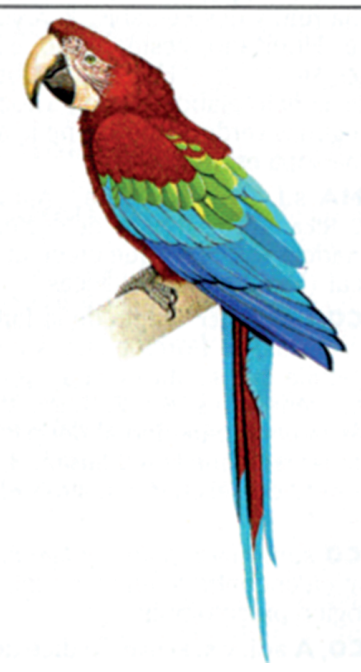

Imagen 9: Pequeño Larousse ilustrado (“Guacamayo 501”).

Veamos también el caso de algunas plantas cuyo origen no es americano, pero llegaron a América desde la época colonial y actualmente su cultura está extendida y arraigada en el continente americano. Es el caso del término "plátano" que aparece en nuestro corpus 10 veces, 9 para evocar el fruto que se come cocinado y una para designar la planta. Veamos la definición muy completa que presenta el NDC (ver Imagen 11).

Este término se traduce sistemáticamente como "banane", pero sabemos que "banane" designa en Colombia el "banano", fruto que se come crudo. Es una realidad del "plátano" que correspondería en francés a "plantain", "banane plantain" o "banane légume". La carga cultural de esa palabra solo se puede observar en el NDC y no en los diccionarios generales. En el caso del DLE, vemos que la tercera 
guacamaya $f E$ - zool Nombre de varias especies de grandes papagayos que habitan las selvas de las tierras cálidas. Alcanzan, en general, hasta $60 \mathrm{~cm}$ de largo y se diferencian entre sí sobre todo por el color de su plumaje (Ara spp.) [E: guacamayo] $* \sim$ bandera $E$ - zool Especie de $\rightarrow$ guacamaya, en su mayor parte de color escarlata. La parte baja del lomo, la rabadilla y las coberteras supracaudales son de color azul claro, las coberteras medias de las alas, amarillas, y el resto de las plumas, azules (Ara macao). $\| \sim$ azul y amarilla $E$ - zool Especie de $\rightarrow$ guacamaya de color azul brillante en la parte de arriba y amarillo encendido en la de abajo (Ara ararauna). $\| \sim$ roja y azul $E$ zool Especie de $\rightarrow$ guacamaya que presenta un plumaje llamativo en el que alternan los colores escarlata, azul y verde. De la punta de la cola al pico puede llegar a los $90 \mathrm{~cm}$ (Ara chloroptera). $\| \sim$ verde $E$ - zool Especie de $\rightarrow$ guacamaya de plumaje mayormente verde, con la frente escarlata y la parte baja del lomo, la rabadilla y las coberteras supracaudales de color azul (Ara militaris).

Imagen 10: NDC (“Guacamaya 202”).

acepción del término "plátano" corresponde al fruto, pero al leer la definición observamos que se trata de lo que en Colombia se llama "banano", es decir la baya que se come cruda y no a la baya que se come cocida. Puesto que este diccionario (DLE) recoge primordialmente el uso de España, concluimos que en ese país "plátano" designa lo que en Colombia se llama "banano". Y en este caso es a partir de esa realidad española que han trabajado los traductores (ver Imagen 12).

Esta observación es igualmente válida para el otro diccionario general de nuestro estudio (ver Imagen 13).

Los traductores no toman en cuenta la lexicultura de este término ni de la diferencia marcada entre "plátano" y "banano" en Colombia. En el caso de la frase "patacones de plátano verde" que aparece en la novela El amor en los tiempos del cólera, Annie Morvan propone la traducción "rondelles de bananes vertes". Esta frase en español es interesante porque presenta dos colombianismos: "patacón” y “plátano”. Un “patacón”, en la Costa Atlántica colombiana, corresponde a una rebanada gruesa de plátano que se aplasta y que luego se frita para acompañar las comidas. Es muy raro usar el banano para hacer este tipo de preparación. Estos elementos lexiculturales se encuentran bien descritos en los diccionarios de colombianismos de nuestro corpus, aquí presentamos las definiciones, por eso estas obras son de gran utilidad para el traductor (ver Imágenes 14 y 15). 
plátano $m$ tamb bot Planta de la familia de las musáceas que alcanza de 3 a $5 \mathrm{~m}$ de altura. Tiene hojas grandes, alargadas, de color verde claro y brillantes. Sus flores crecen en grandes racimos colgantes. El fruto, alargado, de cáscara verde y pulpa amarilla, es parecido al $\rightarrow$ banano, pero, a diferencia de éste, sólo puede ser consumido una vez sometido a cocción (ya sea frito, hervido o asado). Es planta de climas cálidos y templados; se cultivan numerosas variedades (Musa paradisiaca). | Fruto de la planta del $\rightarrow$ plátano [Col +: (plátano) hartón]. | Cund coloq Abultamiento grasoso que se forma en la cintura de las personas por falta de ejercicios y exceso de comida [ $E$ : michelín; Col: llanta; Valle: banano]. $*(\sim)$ amarillo $E$ Costa atl Fruto maduro de la planta de $\rightarrow$ plátano. Se lo llama así cuando, a diferencia del $\rightarrow$ (plátano) verde, ha madurado por completo y su cáscara se ha puesto de color amarillo [Col: (plátano) maduro]. $\|(\sim)$ banano $E$ - Fruta de una planta parecida al $\rightarrow$ plátano (Musa sapientum). A diferencia del fruto de éste, se puede comer crudo $[E$, Col +: plátano; Costa atl: (plátano) guineo; Cund: habano]. $\|(\sim)$ bocadillo E-Fruto de una planta parecida al $\rightarrow$ plátano (Musa acuminata). Se caracteriza por su tamaño pequeño y sabor dulce. $\|(\sim)$ cachaco $E$ Tol, Valle Fruto de una planta parecida al $\rightarrow$ plátano (Musa balbisiana). Se caracteriza por ser muy grueso y pequeño y se come cocido o frito [Cund: (plátano) popocho; Cund, Llanos: (plátano) topocho; NStder, Stder: mataburros]. $\|(\sim)$ guineo $E$-Costa atl Fruto de una planta parecida al $\rightarrow$ plátano (Musa sapientum). A diferencia del fruto de éste, se puede comer crudo $[E, \mathrm{Col}+$ : plátano; Col: (plátano) banano; Cund: habano]. $\|(\sim)$ hartón $E$-Fruto de la planta de $\rightarrow$ plátano [ $\mathrm{Col}+:$ plátano]. $\|(\sim)$ maduro $E$ - Fruto maduro de la planta de $\rightarrow$ plátano. Se lo llama así cuando, a diferencia del $\rightarrow$ (plátano) verde, ha madurado por completo y su cáscara se ha puesto de color amarillo [Costa atl: (plátano) amarillo]. $\|(\sim)$ manzano $E$ - Fruto de una planta parecida al $\rightarrow$ plátano (Crataegus stipulosa). Se caracteriza por su tamaño pequeño y su sabor semejante al de la manzana. Se puede comer crudo. $\|(\sim)$ popocho, var $(\sim)$ topocho $E$ Cund Fruto de una planta parecida al $\rightarrow$ plátano (Musa balbisiana). Se caracteriza por ser muy grueso y pequeño y se come cocido o frito [Cund +, Llanos: (plátano) topocho; NStder, Stder: mataburros; Tol, Valle: (plátano) cachaco]. $\|(\sim)$ topocho $E$ - Cund, Llanos $\rightarrow$ (plátano) popocho. $\| \sim$ verde $E$ Fruto verde de la planta de $\rightarrow$ plátano. Se lo llama así cuando, a diferencia del $\rightarrow$ (plátano) maduro, ha alcanzado su desarrollo normal, pero conserva aún su cáscara verde.

Imagen 11: NDC (“Plátano 329”).

Otra observación importante concierne los términos "pollera" (2 ocurrencias) y "pollerín" (8 ocurrencias). El primero es un término marcado diatópicamente en Colombia que se usa en la Costa Atlántica y designa un tipo de falda muy particular (falda larga y amplia). "Pollerín" también es un término típico de la Costa Atlántica, utilizado por Gabriel García Márquez en Cien años de soledad y en $E l$ amor en los tiempos del cólera. Estas realidades hacen parte de la cultura del caribe y de su folclor. "Pollera" aparece en los diccionarios generales de nuestro estudio, en el DLE como una acepción marcada diatopicamente con las indicaciones América Meridional, Nicaragua y República Dominicana. En el Pequeño Larousse ilustrado el término (cuarta acepción) está marcado únicamente con América Meridional. En el NDC encontramos la extensión geográfica del uso del término en Colombia (Costa Atlántica) y explicaciones sobre las características de este tipo de falda (ver Imágenes 16 a 19).

Cuando observamos las traducciones, encontramos los términos "jupe", "jupon" et "cotillon". "Jupe” corresponde a un término no marcado, es el hiperónimo "falda". Un "jupon" se pone debajo de una falda, corresponde a una "enagua". Es decir que, la traducción de los colombianismos por términos de nivel estándar hace que una parte del mensaje del autor se pierda puesto que "pollera" 


\section{plátano}

Del lat. platănus, y este del gr. $\pi \lambda$ átavos plátanos.

1. m. Árbol de la familia de las platanáceas, con una altura de 15 a 20 o más metros y amplia copa, tronco cilíndrico, de corteza lisa de tono claro, verde grisáceo, que se renueva anualmente, desprendiéndose en placas irregulares, hojas caedizas y alternas, de limbo amplio, palmeadolobuladas, con pecíolo ensanchado en su base, que recubre la yema subsiguiente. Es árbol de sombra, muy apreciado para plantaciones lineales en calles y paseos. Su madera blanca rosada, de dureza media, ofrece un bello jaspeado y se presta para trabajos de ebanistería.

2. $m$. Planta herbácea de grandes dimensiones, que en algunos países llaman banano. Pertenece a la familia de las musáceas. Alcanza una altura de 2 a $3 \mathrm{~m}$ y un fuste de unos $20 \mathrm{~cm}$ de diámetro, formado por las vainas de las hojas, enrolladas apretadamente unas sobre otras y terminadas en un amplio limbo, de unos $2 \mathrm{~m}$ de longitud y unos $30 \mathrm{~cm}$ de anchura, redondeadas en su ápice. El conjunto de estas hojas forma el penacho o copa de la planta.

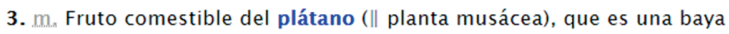
alargada, de diez a quince centímetros de longitud, algo encorvada y de corteza lisa y amarilla.

4. m. Pan, y. P. Rico, plátano grande.

\section{plátano falso}

1. m. Árbol frondoso, botánicamente incluido en los llamados arces, cuyas hojas, amplias y palmeado-lobuladas, recuerdan las del verdadero plátano de sombra.

\section{plátano fruta}

1. m. Cuban plátano que se puede comer crudo.

\section{plátano grande}

1. m. Fruto comestible de una planta musácea de origen indo-malayo, llamada higuera de Adán y muy cultivada hoy en el África tropical, que es mucho más grande, encorvado y verde al exterior que el plátano común.

\section{plátano guineo}

1. m. Fruto de una planta musácea del mismo género que la higuera de Adán, procedente de una especie originaria de la India y muy cultivada en América Central y las Antillas.

\section{plátano manzano}

1. m. . Cupa, Méx. y Perún Variedad de plátano cuyo sabor recuerda al de la manzana.

\section{plátano roatán}

1. m. Méx plátano grande.

\section{plátano verde}

1. m. Cuba.. Y Pan. plátano grande.

estar alguien más pelado que un plátano

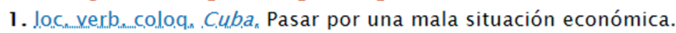

no comer plátano por no botar la cáscara

1. loc. verb, Perú Ser tacaño y cicatero.

mancha de plátano

Imagen 12: DLE (“Plátano”). 
PLÁtANO s.m. (lat. platanus, del gr. plátanos). Banano, planta y fruto. 2. Árbol platanáceo de hasta 3 o $4 \mathrm{~m}$. de alt., gran longevidad (de 500 a 2000 años), fruto en nuececilla,cuya corteza se desprende por placas y que suele plantarse en plazas y paseos. $\diamond$ Plátano falso Árbol de corteza lisa,con hojas de color verde oscuro por el haz y amarillo azulado por el envés.

Imagen 13: Pequeño Larousse ilustrado (“Plátano 806”).

patacón m. Rebanada frita de plátano ver-

de. $\| \sim$ pisao. Variedad de patacón.

Imagen 14: Breve diccionario de colombianismos (“Patacón 82”).

patacón $m \neq$ Rebanada de $\rightarrow$ plátano ver-

de cortada a lo ancho, despachurrada y frita

en aceite.

Imagen 15: NDC (“Patacón 307”).

\section{pollero, ra}

Del lat. pullarius.

1. m.... y. Persona que tiene por oficio criar y vender pollos.

2. m. y. . Méx. Persona que transporta trabajadores indocumentados a los Estados Unidos de América.

3. m. Lugar en que se crían pollos.

4. m. El. Salk. Hombre que transporta trabajadores indocumentados a los Estados Unidos de América.

5. f. pollero (II lugar en que se crían pollos).

6. f. Especie de cesto de mimbres o red, angosto de arriba y ancho de abajo, que sirve para criar los pollos y tenerlos guardados.

7. f. Andador en forma de campana, hecho de mimbres, que se pone a los niños para que aprendan a andar sin caerse.

8. $f$ Falda que las mujeres se ponían sobre el guardainfante y encima de la cual se asentaba la basquiña o la saya.

9. f. Am. Mer...Nic....y. R. Dom. Falda externa del vestido femenino.

10. f. Col. y Pan. Traje típico femenino de Panamá y de la costa norte de Colombia, que consta de una blusa y una falda de amplio vuelo, finamente bordadas.

Imagen 16: DLE (“Pollero, ra”).

y "pollerín" corresponden a una realidad cultural muy precisa y a unos valores que el escritor quiere hacer llegar al lector. El término "cotillon" que aparece marcado en el CNRTL como "vielli" ("anticuado") representa un tipo de falda usado sobre todo por las mujeres del campo. El uso de este término implica una 
Pollera s.f. Sitio en que se crían los pollos. 2. Cesto estrecho de boca y ancho de base que sirve para criar y tener pollos. 3. Utensilio de mimbre acampanado en que se ponía a los niños que todavía no sabían andar. 4. Amér. Merid. Falda de mujer.

Imagen 17: Pequeño Larousse ilustrado (“Pollera 813”).

pollera $f \neq z$ ool $\rightarrow$ (araña) pollera. Costa atl Prenda del vestido femenino consistente en una tela suelta, de diferentes hechuras, que se sujeta en la cintura y cubre la mitad inferior del cuerpo hasta las rodillas o más abajo [E, Col: falda; Ant: funda].

Imagen 18: NDC (“Pollera 332-333”).

pollerín $m E$ - Costa atl Falda interior de mujer [E, Col +: enagua].

Imagen 19: NDC (“Pollerín 333”).

indicación geográfica (el campo) y puede mostrar de alguna forma un tipo de variación diatópica.

Ahora veamos el término "sancocho" que aparece 7 veces en nuestro corpus y que representa un tipo de sopa muy consumido en Colombia que se prepara con carne, plátano y papas. Se traduce sistemáticamente por “pot-au-feu”, es decir por un término no marcado que no incluye en sus valores un uso regional particular. Aparece en los diccionarios generales y en el NDC (ver Imágenes 20 a 22).

SANCOCHO s.m. Amér. Cocido a base de carne,yuca, banano y otros ingredientes.

Imagen 20: Pequeño Larousse ilustrado (“Sancocho 908”).

\section{sancocho}

1. m. Alimento a medio cocer.

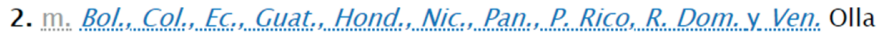
compuesta de carne, yuca, plátano y otros ingredientes, y que se toma en el almuerzo.

3. $m$. Bol., C. Ricay. $R$. Dom, revoltijo (\| conjunto de cosas sin orden).

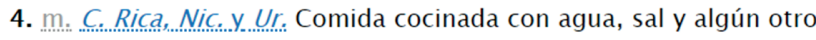
condimento.

5. m. despect. colog. Cubay. Ur. Comida mal preparada, insulsa, pobre en ingredientes.

6. m. Cuba. Resto de comida que se utiliza como alimento para los cerdos.

Imagen 21: DLE (“Sancocho"). 
sancocho $m \neq$ Sopa compuesta de carne, verduras, $\rightarrow$ (plátano) verde $\mathrm{y} \rightarrow$ yuca. $O B S$ : Según la región, pueden variar sus ingredientes. | coloq Barullo, mezcla confusa y desordenada de cosas [ $E$ : batiburrillo; $E$, Col +: embrollo].

Imagen 22: NDC (“Sancocho 365”).

“Cachaco/a” aparece igualmente en nuestro corpus 8 veces y representa en la Costa Atlántica una forma de llamar a las personas que vienen del interior del país, con un matiz despectivo. Aquí encontramos una diferencia dialectal marcada entre dos zonas del país en cuanto al uso de este término pues en el interior del país, y particularmente en Cundinamarca, este designa generalmente una persona de buenos modales y bien vestida. El DLE integra este colombianismo, pero recoge únicamente el uso del interior del país y no mencionan el de la Costa Atlántica. El Pequeño Larousse indica (segunda acepción) el matiz negativo que puede tener la palabra para designar una persona que cuida su apariencia de forma extrema, pero no el uso costeño, el cual está bien descrito en los diccionarios de colombianismos (ver Imágenes 23 a 27).

cachaco, ca

1. adj: Col. Dicho de un joven: Elegante, servicial y caballeroso.

2. m. y. . . Col., Persona bien educada.

3. m. y. f. rur. P. Rico, Español de buena posición económica.

4. m. despect. Perú. Miembro del cuerpo de Policía.

5. m. despect. Perú. militar (\| hombre que profesa la milicia).

Imagen 23: DLE (“Cachaco, ca”).

CACHACO, A adj. Colomb. Se dice del joven elegante, servicial y caballeroso. 2. Colomb., Ecuad. y Venez. Lechuguino, petimetre. $\bullet$ s.m. Perú. Desp. Policía. — s. P. Rico. Nombre dado en la zona rural de la isla a los españoles acomodados.

Imagen 24: Pequeño Larousse ilustrado (“Cachaco,a 179”).

Si observamos la traducción de "cachaca", en Cien años de soledad vemos que los esposos Durand escogieron el término "précieuse" que designa a una persona muy refinada, pero llegando a ser muy artificial y un poco pretenciosa, con una marca estilística "peyorativa" según el CNRTL. "Cachaca" es un término marcado geográficamente, que fue traducido por otro que varía únicamente de manera estilística. La traducción de Claude Couffon y de Annie Morvan nos parece más adecuada en este caso porque hay una indicación geográfica: "fille(s) (venues) des Andes". 
cachaco, -a 1. $m / f E$ - Persona bien educada, de buenos modales. | Ant, Cald, Cund Persona de apariencia elegante y bien vestida. OBS: Puede tener, según el contexto, una connotación despectiva, en el sentido de: lechuguino, petimetre. | Costa atl Natural del interior de Colombia [Costa atl $+:$ interiorano]. $O B S$ : Suele tener una connctación despectiva. $\mid 2$ adj $E$ - Bien educado, de buenos modales [E, Col + : correcto]. $A n t$, Cald, Cund Elegante, bien vestido [ $E$ : peripuesto; Col: V. perchudo]. OBS: Puede tener, según el contexto, una connotación despectiva, en el sentido de: lechuguino, petimetre. | Costa atl Relativo o propio del interior de Colombia. OBS: Suele tener una connotación despectiva.

cachaco $m E$ - Tol, Valle $\rightarrow$ (plátano) cachaco.

Imagen 25: NDC (“Cachaco,-a 63”).

Cachaco(a) s. y adj. 1. -Originalmente designaba un Caballero muy bien vestido. "¿Para dónde va tan cachaco?". 2. -Pasó a ser genérico de bogotano y luego de toda persona de la zona andina, calificada así por los costeños: "Cachaco, palomo y gato: tres animales ingratos". (Por esta generalización los colombianos nos dividimos en cachacos y costeños, excepto los cartageneros que son los cachacos de la Costa, por habitar una ciudad señorial).

Imagen 26: DC (“Cachaco(a) 91”).

cachaco, a adj. Bog. Dicho de una persona, de finas maneras, bien educada. Es muy cachaco, siempre atento con sus invitados. U. t. c. s. 2. Elegante en el vestir. 3. Costa Atl. Dicho de una persona, que es del interior del país, especialmente de Bogotá.

Imagen 27: Breve diccionario de colombianismos ("Cachaco,a 27").

Observemos ahora el término "bolillo" que aparece dos veces en Cien años de soledad y que designa en Colombia un tipo de arma generalmente de madera, alargado, usado por las fuerzas policiales. Este término se traduce por "bâton", que no muestra la carga lexicultural de la palabra porque un "bolillo" hace parte del traje de un policía colombiano y su uso está reservado a personas que pertenecen a esta institución o al gremio de los agentes de seguridad. 
Utilizar "bâton", es decir "palo", cambia completamente el mensaje, cualquier persona puede armarse de un palo, lo que equivale a decir que los policías no estaban bien equipados. Encontramos "bolillo" en todos los diccionarios de colombianismos y en los diccionarios generales el término aparece como una acepción que tiene la marca Colombia (ver Imágenes 28 a 32).

\section{bolillo}

\section{Del dim de bolo ${ }^{1}$}

1. m. Palo pequeño y torneado que sirve para hacer encajes y pasamanería. El hilo se arrolla o devana en la mitad superior, que es más delgada, y queda tirante por el peso de la otra mitad, que es más gruesa.

2. $m$. En la mesa de trucos, hierro redondo, de diez a doce centímetros de alto, puesto perpendicularmente en una cabecera, enfrente de la barra.

3. $m$. Horma para aderezar vuelos de gasa o de encaje.

4. $m$. Vuelo de gasa o de encaje.

5. $m$. Hueso a que está unido el casco de las caballerías.

6. $m$. Cols Instrumento cilíndrico, de unos $50 \mathrm{~cm}$ de longitud, que los agentes de la Policía usan como signo de autoridad.

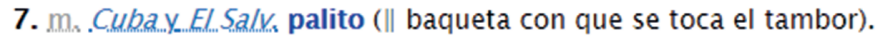

8. $m$. EG, rodillo (II cilindro para estirar la masa).

9. $m$. El Salv. y. Méx Cierto tipo de pan blanco.

10. m. pl. Barritas de masa dulce.

puro bolillo

1. expr... Méx. Nada, en absoluto.

valer alguien o algo bolillo

1. loc. verb. Méx valer muy poco o nada. encaje de bolillos

Imagen 28: DLE (“Bolillo”).

BOLILLO s.m. Palo pequeño cilíndrico al cual se enrollan los hilos para hacer encajes y pasamanería. 2. Hierro redondo colocado perpendicularmente en una cabecera, enfrente de la barra, en la mesa de billar. 3. Hueso al que se une el casco o uña de las caballerías. 4. Colomb. Porra de caucho o madera usada por la policía. 5. C. Rica. Palo pequeño para tocar el tambor. 6. Méx. Pan alargado, esponjoso, de corteza dura y con los extremos rematados con dos bolitas. $<$ bolillos s.m.pl. Barra pequeña de masa dulce.

Imagen 29: Pequeño Larousse ilustrado (“Bolillo 161”). 
bolillo $\mathrm{m}$. Instrumento cilíndrico de madera o goma, de unos cincuenta centímetros de longitud, que usan los agentes de policía y los vigilantes.

Imagen 30: Breve diccionario de colombianismos ("Bolillo 25").

bolillo $m$ tamb Palo grueso y fuerte que usan los agentes de policía como arma [E: porra; Cund: macana]. | Boy, NStder Rebanada de $\rightarrow$ plátano verde cortada de a lo ancho y frita en aceite [Col: patacón; Ant, Cald, Cauca, Valle: tronco].

Imagen 31: NDC (“Bolillo 50").

Bolillo I. -Porra de los agentes de policía. 2. -Rodillo para amasar.

Imagen 32: DC (“Bolillo 87").

Gracias a la marca "E” del NDC, vemos que el término equivalente a "bo lillo” en España es “porra”.

Terminemos está presentación con el término "parranda” que tiene 50 ocurrencias en nuestro corpus, 23 en Cien años de soledad, 16 en Crónica de una muerte anunciada y 11 en El amor en los tiempos del cólera. "Parranda" es una fiesta animada con música y bebidas alcohólicas. En el DLE el término aparece con diferentes marcas diatópicas, pero sin una marca colombiana que debería aparecer puesto que el término es de amplio uso en ese país. En el Pequeño Larousse tampoco aparece esa marca (ver Imágenes 33 y 34).

\section{parranda}

Etim. disc.

1. f.. Cuadrilla de músicos o aficionados que salen de noche tocando instrumentos de música o cantando para divertirse.

2. f. colog. Juerga bulliciosa, especialmente la que se hace yendo de un sitio a otro.

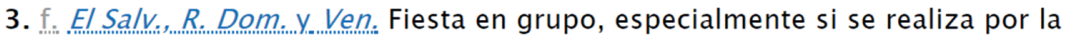
noche y con bebidas alcohólicas.

4. $\mathrm{f} . \mathrm{Ven}$. Manifestación folclórica en la que un grupo de personas canta y baila alrededor de una persona disfrazada, generalmente de animal, que es el tema central de las canciones.

Imagen 33: DLE (“Parranda”).

En los diccionarios de colombianismos, sobre todo en el DC, podemos observar que el uso del término está marcado dentro del país. 
PARRANDA s.f. Juerga, especialmente la que consiste en ir de un lugar a otro: salieron de parranda por los bares de la ciudad.

Imagen 34: Pequeño Larousse ilustrado (“Parranda 769”).

Parranda s. En la Costa, reunión de amigos para celebrar algo, fiesta popular para tomar trago, oír música y bailar. Es famosa la parranda vallenata. Véanse vallenato. Parrandear(se) v. (pronunc. parrandearse) Malgastar.

Imagen 35: DC (“Parranda 179”).

\section{parranda $f$ tamb coloq Muchedumbre o abundancia de personas o cosas.}

Imagen 36: NDC ("Parranda 304").

Es interesante observar que en francés el término se traduce por una gran cantidad de palabras, con estrategias particulares según el traductor. Los esposos Durand escogen sobre todo términos no marcados como "fête", "festin", "festivité", "noce”, "débauche”, “orgie” y "réjouissances". En su traducción vemos solamente un término familiar o anticuado (CNRTL): "ripaille". Claude Couffon decide servirse más de términos marcados diafásicamente en su traducción con palabras como "bombance", "nouba” y “cuite”. Usa además "noce”, "bacchanale”, "festin", "fête” y "beuverie". Annie Morvan también explora la variación estilística con los términos "bombance", "bamboche", "bamboula", pero puede utilizar otros términos no marcados como "fête", "réjouissances" y "festivités".

\section{A modo de conclusión}

De manera general, podemos decir que esta investigación ha permitido crear un corpus de colombianismos léxicos y sus traducciones que deseamos extender a otras obras del autor y a otros autores colombianos con el fin de presentar en libre acceso estos datos para los interesados en la variación en general y en el español de Colombia en particular.

En cuanto a las obras lexicográficas, podemos decir que los diccionarios de colombianismos presentan elementos de gran riqueza lexicultural, su uso es, por lo tanto, indispensable en la traducción de un texto literario colombiano. Los diccionarios generales, como ya lo hemos evocado, incluyen muchos diatopismos hispanoamericanos, Colombia es un país que aparece bien representado 
en cuanto al número de marcas diatópicas en estos diccionarios, pero con gran frecuencia las definiciones no reflejan los valores lexiculturales colombianos. Una tarea pendiente de la lexicografía colombiana es la creación de un diccionario global que sobrepase la tradición contrastiva y que incluya valores lingüísticos y culturales de esta variedad.

Con respecto a las traducciones, hemos observado varias estrategias para aprehender la variación diatópica. Si un término se observa marcado únicamente por esta variación, la estrategia de los esposos Durand es casi sistemática optando por la traducción a un término estándar en la versión francesa. Pero si el término varía además de forma estilística, los traductores prefieren conservar esta variación estilística en el texto en francés. Algunas tentativas de introducir elementos geográficos se observan en las traducciones de Claude Couffon y de Annie Morvan. Pero el único intento de traducir la variación diatópica aparece en el texto de Claude Couffon, con el término "canoa”. Este término es de gran valor simbólico porque es la primera palabra hispanoamericana introducida en un diccionario europeo, el diccionario de Nebrija publicado en 1495.

\section{Canoa nave deun madero, monorylumol.}

Imagen 37: (“Nebrija 38”).

Claude Couffon propone en su traducción “canot”, término marcado geográficamente, puesto que se utiliza sobre todo en el Canadá. En Francia se usa generalmente “canoë” y Annie Morvan así lo tradujo en El amor en los tiempos del cólera.

Terminaremos señalando que desde un punto de vista lingüístico-cultural los textos traducidos de nuestro corpus presentan difícilmente valores equivalentes en cuanto a la variación diatópica del texto origen y no ofrecen la misma riqueza lexicultural que el autor introduce en español. Es decir que los traductores, gracias a sus conocimientos y a su visión de la lengua y de la cultura del texto origen, proponen una nueva visión de ese texto pasando por valores lexiculturales de la lengua meta. Este estudio muestra que la variación diatópica del español se toma muy poco en cuenta en las traducciones y que la intencionalidad del autor en cuanto a esta variación desaparece. Sin embargo, el traductor introduce una idea general de esta variación geográfica, no por medio de valores diatópicos sino generalmente por medio de valores diafásicos de la lengua y de la cultura meta.

\section{Bibliografía}

Alvar Ezquerra, Manuel. “Lexicografía dialectal”. Estudios de Lingüística de la Universidad de Alicante, $\mathrm{n}^{\circ} 11,1996-97, \mathrm{pp} .79-108$. 
Bohorquez, Jesús Gútemberg. Concepto de "americanismo" en la historia del español: punto de vista lexicológico y lexicográfico. ICC, 1984.

Cuervo, Rufino José. Obras inéditas de Rufino J. Cuervo. Ed. José Félix de Restrepo. Ministerio de Educación Nacional, 1944.

Dosse, François. Les hommes de l'ombre. Portraits d'éditeurs. Perrin, 2014.

Galisson Robert. "Cultures et lexicultures. Pour une approche dictionnairique de la culture partagée”. Annexes des Cahiers de linguistique hispanique médiévale, Hommage à Bernard Pottier, vol n 7, 1988, pp. 325-341.

García Márquez, Gabriel. L’Amour aux temps du choléra. Trad. Annie Morvan. Éditions Grasset, 1987.

---. El amor en los tiempos del cólera. Oveja negra, 1985.

--.. Chronique d'une mort annoncée. Trad. Claude Couffon. Éditions Grasset, 1981.

--.. Crónica de una muerte anunciada. Oveja negra, 1981.

--.. Cent ans de solitude. Trad. Claude y Carmen Durand. Éditions du Seuil, 1968.

--.. Cien años de soledad. Sudamericana, 1967.

Marling, William. Gatekeepers: the emergence of World Literature and the 1960s. Oxford University Press, 2016.

Montes Giraldo, José Joaquín. Dialectología general e hispanoamericana: orientación teórica, metodológica y bibliográfica. ICC, 1995.

Montoya, Ramiro. “Guayaba.”/“Cachaco(a).”/“Bolillo.”/“Parranda.” Diccionario comentado del español actual en Colombia, 3a edición. Visión Net, 2006, pp. 143/91/87/179.

Nebrija, Antonio de. "Canoa." Dictionarium ex hispaniensi in latinum sermone o Vocabulario español-latino. 1495 [ ], p. 38.

Ospina, William. Pa que se acabe la vaina. Planeta, 2018.

Otálora de Fernández, Hilda. Léxico del habla culta de Santafé de Bogotá. ICC, 1997.

"Patacón."/“Cachaco, a."/"Bolillo." Breve diccionario de colombianismos. Coord. Carlos Patiño Rosselli, 4a edición. Academia Colombiana de la Lengua, 2012, pp. 82/25/23.

Pottier-Navarro, Huguette. “El concepto de americanismo léxico". Revista de Filología Española, vol. LXXII, n 3-4, 1992, pp. 297-312.

Quemada, Bernard. Les dictionnaires du français moderne 1539-1863. Didier, 1968.

Rabanales, Ambrosio. Introducción al estudio del español de Chile, determinación del concepto de chilenismo. Universidad de Chile, Instituto de Filología, 1953.

Rona, José Pedro. “¿Qué es un americanismo?”. Actas, informes y comunicaciones del Programa Interamericano de Lingüística y Enseñanza de Idiomas. El simposio de México, enero de 1968. Universidad Nacional Autónoma de México, 1969, pp. 135-148.

"Yuca.”/“Guayaba.”/“Guacamaya.”/“Plátano.”/“Patacón.”/“Pollera.”/“Pollerín.”/ "Sancocho."/“Cachaco."/“Bolillo."/“Parranda." Nuevo Diccionario de Americanismos. Tomo I, Nuevo diccionario de colombianismos. Dir. Günter Haensch y Reinhold Werner. ICC, 1993, pp. 421-422/210/202/329/307/332-333/333/365/63/50/304.

"Yuca."/“Guayaba."/“Guacamayo.”/“Plátano.”/“Pollera.”/“Sancocho."/“Cachaco.”/ “Bolillo."/“Parranda.” Pequeño Larousse ilustrado 2012. Larousse editorial, 2011, pp. 1053/504/501/806/813/908/179/161/769.

"Yuca."/“Guayaba."/“Guacamayo.”/“Plátano."/“Pollero-a.”/“Sancocho.”/“Cachaco.”/ “Bolillo."/"Parranda.” Diccionario de la lengua española, 23. a ed., actualización 2017. Real Academia Española. http://dle.rae.es/, consultado el 13 de junio de 2018. 